\title{
Evaluation of biological activity of aqueous extract of Ailanthus Altissima (Mill. Swingle)
}

\begin{abstract}
Assessment of the Effect of the Water Extract of Ailanthus altissima (Mill. Swingle). In this study the effect of the water extract of Ailanthus altissima (Mill. Swingle) in photosynthesis and growth components of corn and seed germination of corn, tomato and Ailanthus seeds was assessed. Results showed that the extract adversely influenced photosynthesis and growth components of corn and seed germination of corn and tomato. No effect was observed on Ailanthus seeds germination.
\end{abstract}

Volume 2 Issue 5 - 2015

\author{
Paul Bouchagier,' Maria loannou-Skender,' \\ Efstathia Scots, ${ }^{2}$ Efstathia Efthimiadou, ${ }^{3}$ \\ Panagiotis Efthymiadis ${ }^{3}$ \\ 'Department of Organic Farming, Greece \\ ${ }^{2}$ Department of Ecology and Environment, Greece \\ ${ }^{3}$ Agricultural University of Athens, Greece
}

Correspondence: Paul Bouchagier, Department of Organic Farming, Argostoli, Greece,

Email ioannou_skenter@hotmail.com

Received: July 26, 2014 | Published: August 21, 2015

\section{Introduction}

Ailanthus altissima (Mill. Swingle) is a tree-weed belonging to the family Simaroubaceae. Originally from Southeast Asia (China, Vietnam). This is a very aggressive species that has become a serious problem across Europe and in the southern states of the United States of America. In recent years, growing at a rapid pace and in Greece, particularly in urban centers. The purpose of this study is to evaluate the biological activity of the aqueous extract of Ailanthus seeds studying its effect on photosynthetic characteristics of maize as well as in germinating seeds of maize (Zea mays, L. variety Rugosa Bonanza), tomato (Lycopersicum esculentum, L. variety. Marmade) and Ailanthus altissima.

\section{Materials and methods}

The effect of aqueous extract of Ailanthus seeds in photosynthetic and agronomic characteristics of maize was studied in an experiment in plastic pots of $15 \mathrm{~cm}$ diameter and a capacity of 5liters, in soil from the field of Agriculture Laboratory of AUA. Sowing took place on 21 August 2007. After germination, remained in each pot seedlings of maize. The interventions of the experiment were:

i. Maize plants (control)

ii. Maize plants under the effect of an aqueous extract obtained from leaves Ailanthus seeds by immersion for 8 hours at ambient temperature water

iii. Maize plants under the effect of an aqueous extract obtained from leaves of Ailanthus seeds by immersion for 2hours at nerothermokrasias 40C.

In both cases extraction was $700 \mathrm{~g}$ leaf middle age in one liter of water. In each treatment there were 12 experimental items (pots). The effect of the extract began with sowing and were daily root irrigation. In developing maize seedlings were measured at regular intervals stomatal resistance, transpiration of leaves and the total rate of photosynthesis. The experiment was completed on October 5, 2007 by measuring the dry weight of the shoot, the number of sheets and the diameter of the corn stalk.

The study of the effect of aqueous extract of seed germination Ailanthus seeds in the same species (aftopatheias case) was to experiment dishes ( $9 \mathrm{~cm}$ diameter) in steady state chamber (i: $25 \mathrm{C}$, $8 / 16 \mathrm{~h}$ photoperiod). On each plate there was a seed or a fruit Ailanthus seeds respectively. The effect of the extract was made by applying to the plates aqueous extract obtained from leaves Ailanthus seeds by immersion for 2 hours in water at $40 \mathrm{C}$.

To study the effect of the aqueous extract of Ailanthus seeds in tomato seed germination and tomato experiment was made with maize in the plates $(9 \mathrm{~cm}$ diameter) in chamber stable conditions (i: $25 \mathrm{C}$, $8 / 16 \mathrm{~h}$ photoperiod). On each plate there was a seed of equivalent type. The effect of the extract was made by applying to the plates aqueous extract obtained from leaves Ailanthus seeds by immersion for 2 hours in water at $40 \mathrm{C}$. The measurement was recorded daily and the sprouted seeds and radicle length.

\section{Results}

Under the effect of the extract of Ailanthus seeds increased stomatal resistance in maize leaves and decreased leaf transpiration and the total rate of photosynthesis. The change was statistically significant in all three features $(\mathrm{F}<0.0001)$. Especially the resistance stomata in the leaves of maize, the increase was stronger under the effect of surgery (c) (Figure 1).

Also under the effect of the extract significantly decreased the dry weight $(\mathrm{F}<0.0001)$ and the diameter $(\mathrm{F}: 0.0002)$ of the stem and the number of sheets (F:0.0002) maize plants. In particular under the effect of the surgery (c), the dry weight of the maize stem decreased by $89 \%$, the diameter of the stem $58 \%$ and the number of the sheets by $49 \%$. The aqueous extract did not affect the germination of seeds of Ailanthus or when the seeds were naked or were in the fruit. In contrast, the aqueous extract slowed the germination of seeds of maize and tomato and elongation of the radicle. The effect was more pronounced in tomato. 


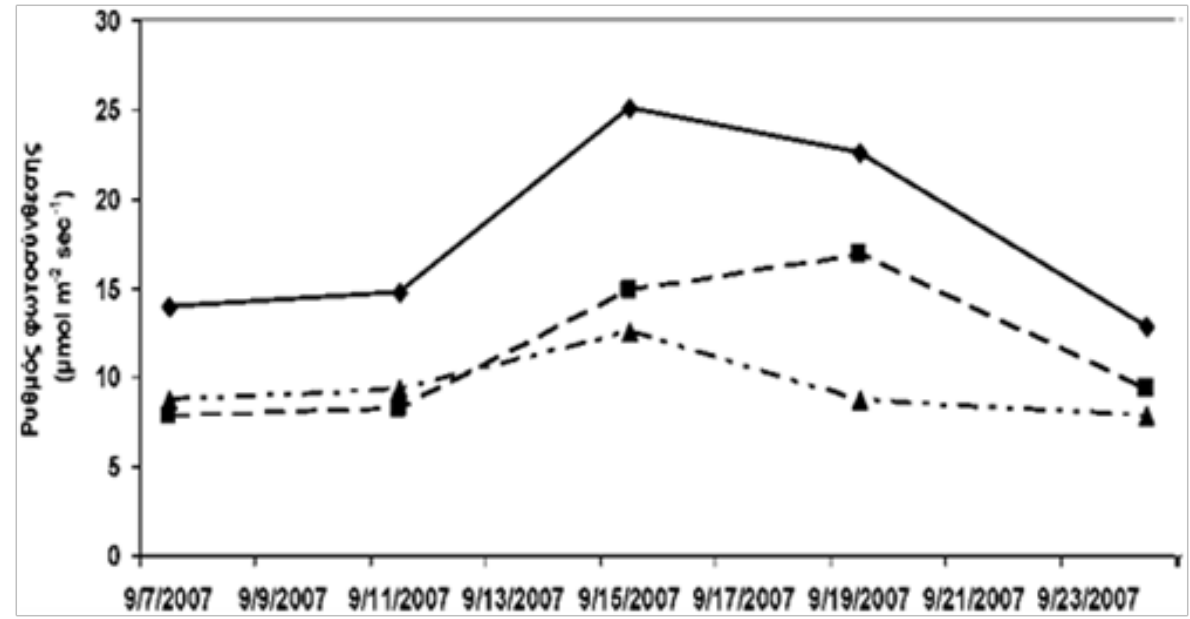

Figure I Effect of total extract Ailanthus seeds photosynthetic rate in maize plants.

Witness F - - - Extract (I inc / ment) - $\nabla$ - Extract (I 40C)

\section{Discussion}

The entry of alien plant species hitherto free from these areas remains a serious problem, despite deterrence strategies designed. So where these species acclimated to the new environment is seriously compromising the ecological balance because they propagate freely, since most of the time their entry not accompanied by the entry of natural enemies.

\section{Conclusion}

The case is typical of Ailanthus altissima case prevalence and uncontrolled spread of invasive plant species Kowarik et al. ${ }^{1}$ The ability across the prevalence endemic plant species due in allilopathitiko potential develops. In the present study, the effect of aqueous extracts on physiological functions in vegetative plant growth and seed germination (including seeds Ailanthus seeds). The results of the experiments may help to understand the mechanism by which Ailanthus prevails over other plant species.

\section{Acknowledgements}

None.

\section{Conflict of interest}

The author declares no conflict of interest.

\section{References}

1. Kowarik I, Saumel I. Biological floral of Central Europe: Ailanthus altissima (Mill.) Swingle. Perspectives in Plant Ecology, Evolution and Systematics. 2007;8(4): 207-237. 